\title{
1 Title: Phytoplankton traits from long-term oceanographic time-series
}

2 Running page head: Phytoplankton traits from time-series data

4 Crispin M Mutshinda ${ }^{1}$, Zoe V Finkel ${ }^{2}$, Claire E Widdicombe ${ }^{3}$, Andrew J Irwin ${ }^{1}$

$5 \quad{ }^{1}$ Mathematics \& Computer Science, Mount Allison University, Sackville, NB, Canada, E4L $6 \quad 1 \mathrm{E} 6$

$7 \quad{ }^{2}$ Environmental Science, Mount Allison University, Sackville, NB, Canada, E4L 1A7

$8 \quad 3$ Plymouth Marine Laboratory, Prospect Place, Plymouth, UK, PL1 3DH

10 Keywords: Phytoplankton, time-series, traits, growth rate, grazing rate, English Channel

\section{Abstract}

13 Phytoplankton trait-based modeling is a mechanistic approach to describing species and 14 community dynamics in ecosystem models. Trait values are usually extracted from 15 laboratory studies of single species, which presents challenges for understanding the 16 immense diversity of phytoplankton species and the wide range of dynamic ocean

17 environments. Here we use a Bayesian approach and a trait-based model to extract traits 18 for four functional types and ten diatom species from field data collected at Station L4 in 19 the Western Channel Observatory. We find differences in maximum net growth rate, 20 temperature optimum and sensitivity, half-saturation constants for light and nitrogen, and 21 density-dependent loss terms across the functional types. We find evidence of very high 22 linear loss rates, suggesting that grazing may be even more important than commonly 23 assumed and differences in density-dependent loss rates across functional types, indicating

24 the presence of strong niche differentiation among functional types. Very low half25 saturation constants for nitrogen at the functional type level may indicate widespread 26 mixotrophy. At the species level, we find a wide range of density-dependent effects, which 27 may be a signal of diversity in grazing susceptibility or biotic interactions. This approach 28 may be a way to obtain more realistic and better-constrained trait-values for functional 29 types to be used in ecosystem modeling. 


\section{Introduction}

Phytoplankton perform about half of global photosynthesis, form the base of the marine food web and are an important driver of biogeochemical cycles (Field et al. 1998).

34 Model projections of changes in phytoplankton primary production with climate over the next century are extremely variable (Finkel et al. 2010, Finkel 2014). Projections of changes in communities and biogeochemical cycling usually depend on mechanistic models of phytoplankton productivity parameterized with traits of phytoplankton species (Le Quéré et al. 2005, Litchman et al. 2006). The traits used in models vary according to the research questions, but most commonly include maximum growth rate, Arrhenius-like temperature effects on growth rate, half-saturation parameters linking the growth rate to resource availability, and grazing susceptibility (Litchman et al. 2007, Irwin \& Finkel 2016). At present, many of these parameters are not well constrained for phytoplankton communities (Anderson 2005, Irwin \& Finkel 2016).

Phytoplankton are evolutionarily and ecologically diverse and include many phyla and tens of thousands of species (Sournia et al. 1991, de Vargas et al. 2015). This complexity presents several challenges for trait-based modeling. Trait values measured in the lab are almost always determined for a few key species, while their application in models of natural communities usually apply to dozens to thousands of species. The aggregation of similar species into biogeochemically defined functional types greatly simplifies models, but there is no clear way to decide which species should be used as representatives of each functional type (Merico et al. 2004, Le Quéré et al. 2005, Hood et al. 2006). Trait values for species in the same functional type and trait values used in models vary widely, commonly by a factor of 10-100 (Anderson 2005, Irwin \& Finkel 2016). It is not clear how to average trait values across species to represent a functional type since phytoplankton growth rate is a non-linear function of trait values. Furthermore, species well adapted to lab conditions may not be representative of their respective functional types growing in natural communities. A second set of challenges concerns the difficulty of

58 using lab-based estimates of trait values in a field context. Trait values quantified using 59 laboratory cultures under controlled conditions are stable under repeated measurement, 60 but there is a challenge in identifying the most appropriate conditions for culture 61 experiments. For example, the maximum growth rate is commonly estimated in the lab, but 
62 differences in culture conditions from one lab to another means there is always some doubt

63 about the true maximum growth rate for a species (Boyd et al. 2013). Trait-values,

64 including maximum growth rate and nutrient uptake rates, estimated in the field can differ

65 substantially from those measured in the lab (Furnas 1991, Laws 2013, Lomas et al. 2014).

66 Cultures grown under equilibrium conditions in the lab may not reveal key acclimation

67 traits or the consequences of environmental variability that can be crucial to the fate of

68 phytoplankton in natural communities (Grover 1991, Raven 2011). In summary, trait

69 values for most phytoplankton species are not available and we do not currently have

70 enough data to strongly constrain trait values used in functional type models (Anderson

71 2005, Flynn et al. 2015).

72 An approach that addresses many of these challenges for determining trait values

73 for function types is to estimate those values from long-term time series of natural

74 communities observed in the field. Our goal is to obtain quantitative estimates of trait

75 values that define the dynamics of the biomass of phytoplankton functional types. These

76 trait values will be affected by the species that are present in the community, the range of

77 environmental conditions observed, the spectrum of environmental variability, as well as

78 abiotic and biotic interactions, so we call them realized traits in recognition that they are

79 not the fixed traits of a particular species. This label is an echo of the difference between

80 fundamental and realized niches, where the realized niche is measured in a community and

81 can differ from the fundamental niche (Hutchinson 1957, Colwell \& Rangel 2009). Here we

82 obtain realized trait values by fitting a model of biomass dynamics to time series of

83 phytoplankton functional type biomass and coincident environmental conditions. The

84 model describes temporal biomass changes in terms of net growth rate modified by

85 temperature, irradiance, total available nitrogen concentration, and a density dependent

86 loss term. We adopt a hierarchical Bayesian modeling approach and use Markov-chain

87 Monte Carlo (MCMC) methods to simulate from the joint posterior of the model

88 parameters, in particular the traits of interest. Realized trait values estimated from field

89 data may be quite different from trait values obtained in the lab and may vary across

90 communities in different locations. The advantages of these realized traits compared to

91 species-level traits quantified in the lab is that these traits by definition describe observed

92 community dynamics. 
94 Methods

95 Data

96 We used data from the Western Channel Observatory (WCO) oceanographic time-

97 series (www.westernchannelobservatory.org.uk) in the Western English Channel. The

98 WCO data include phytoplankton, zooplankton, and fish trawls together with

99 measurements of several physical and chemical environmental parameters such as

100 temperature, salinity and nutrient concentrations. The data used here were collected at

101 Station $\mathrm{L} 4\left(50^{\circ} 15.00^{\prime} \mathrm{N}, 4^{\circ} 13.02^{\prime} \mathrm{W}\right)$ located about $10 \mathrm{~km}$ south of the Plymouth

102 breakwater with a water column depth of about $50 \mathrm{~m}$ (Harris 2010). We used 349 weekly

103 observations of taxonomically resolved phytoplankton abundance, temperature, nitrate,

104 nitrite, and ammonium concentrations sampled at $10 \mathrm{~m}$ depth in the upper mixed layer and

105 sea-surface irradiance collected over a 7-year period spanning 15 April 2003 through 31

106 December 2009. Average biovolume measurements were recorded for each species

107 (Widdicombe et al. 2010) and converted to carbon content (Menden-Deuer \& Lessard

$1082000)$ to obtain biomass concentrations $\left(\mathrm{mg} \mathrm{C} \mathrm{m}^{-3}\right)$ for each species. We used observations

109 of 193 taxonomic categories identified as 138 species, 27 genera, and 28 size-classes for

110 broader morphological categories. Biomass concentrations were aggregated into four

111 functional types: diatoms, dinoflagellates, coccolithophorids, and phytoflagellates. The

112 phytoflagellate type is taxonomically diverse but is dominated (more than $50 \%$ of the

113 biomass) by unidentified flagellates less than $5 \mu \mathrm{m}$ in diameter. Some species may be

114 benthic or tychoplanktonic. We added together the concentrations of nitrate, nitrite, and

115 ammonium to obtain a single inorganic nitrogen $\left(\mathrm{mg} \mathrm{m}^{-3}\right)$ concentration. Most of the

116 variation in total nitrogen concentration is due to variation in nitrate concentration.

117 Irradiance $\left(\mathrm{mol} \mathrm{m}^{-2} \mathrm{~d}^{-1}\right)$ was measured continuously above the sea-surface near Station L4

118 at Plymouth and averaged over the day. Data for missing weeks were imputed by linear

119 interpolation using the na.approx function from the zoo library in R (R Core Team 2016).

121 The model

122 We describe the multiplicative growth rate of each functional type's biomass as the

123 product of the following 5 components: (i) a net growth rate reduced by limitation due to 
124 either low light or low nitrogen concentration, (ii) a temperature effect, (iii) a density

125 feedback term dependent on the biomass of the focal functional type, (iv) a density

126 feedback term dependent on the biomass of all phytoplankton not in the focal functional

127 type, and (v) a positive multiplicative noise term. The change in biomass from one week to

128 the next (from week $w-1$ to week $w$ ) for each functional type $i$ is modeled by multiplying

129 the biomass in week $w-1$ by the (multiplicative) growth rate according to a stochastic

130 Gompertz model (Saitoh et al. 1997, Mutshinda et al. 2009, Mutshinda et al. 2011). We

131 chose to model the net growth rate as a linear combination of density-independent growth

132 rate and density-dependent losses, which is most appropriate given the lack of direct

133 information about grazing rates, grazer biomass, or viral abundance. Therefore, the

134 biomass concentration $Y_{i, w}$ (in $\mathrm{mg} \mathrm{Cm}^{-3}$ ) of the $i^{\text {th }}$ functional type for each week after the

135 first $(w \geq 2)$ is described by

136

137

$$
Y_{i, w}=Y_{i, w-1} \exp \left\{r_{i, w}+\alpha_{i} \log \left(Y_{i, w-1}\right)+\phi_{i} \log \left(Z_{i, w-1}\right)\right\} \eta_{i, w},
$$

138

139 where $Z_{i, w}$ is the combined biomass concentration of all phytoplankton not including the

$140 \quad i^{\text {th }}$ functional type during week $w$. The growth rate, which appears in the exponent of Eq.

141 (1), is composed of a density-independent component, $r_{i, w}$, and a density-dependent

142 component, $\alpha_{i} \log \left(Y_{i, w-1}\right)+\phi_{i} \log \left(Z_{i, w-1}\right)$. Stochastic noise enters the biomass dynamical

143 model (Eq. 1) through the random multiplicative noise $\eta_{\mathrm{i}, \mathrm{w}}>0$ that we assume to be serially

144 independent and log-normally distributed with median one and mean $\exp \left(\sigma_{i, w}^{2} / 2\right)$, so that

145 the $\log \left(\eta_{i, w}\right)$ are independently zero-mean normal with respective variances $\sigma_{i, w}^{2}$. The

146 unstructured stochastic noise term lumps together the variability due to all un-modelled

147 processes: demographic stochasticity, sampling error and the environmental variability

148 attributable to other variables not included in the model. The log-normal distribution is

149 widely used to describe species abundance and biomass patterns (MacArthur 1960,

150 Sugihara 1980) on both theoretical and empirical grounds. We showed that biomass 
151 distributions at this site are log-normal in an earlier study (Mutshinda et al. 2016). The 152 notation is summarized in Table 1.

153 The traits to be estimated appear in the growth rate terms. The density-independent 154 component of growth rate, $r_{i, w}$, for functional type $i$ from week $w$ - 1 to week $w$ depends on

155 Michaelis-Menten functions of irradiance $\left(P A R, \mathrm{~mol} \mathrm{~m}^{-2} \mathrm{~d}^{-1}\right)$ and nitrogen concentration $(N$, $\left.156 \mu \mathrm{mol} \mathrm{L}{ }^{-1}\right)$, and a function of temperature $\left(T,{ }^{\circ} \mathrm{C}\right)$, according to

$157 \quad r_{i, w}=\mu_{i} \min \left(\frac{P A R_{w-1}}{k_{E, i}+P A R_{w-1}}, \frac{N_{w-1}}{k_{N, i}+N_{w-1}}\right)-\beta_{i}\left|T_{w-1}-\theta_{i}\right|$

158 where $\theta_{i}$ denotes the optimum growth temperature for the biomass of functional type $i$ 159 and $\beta_{i}>0$ is a temperature sensitivity parameter intended to quantify the increase in the 160 density-independent growth rate $r_{i, w}$ for a $1^{\circ} \mathrm{C}$ change in temperature towards the 161 optimum temperature $\theta_{i}$ and vice-versa. The optimal temperatures $\theta_{i}$ for growth of each 162 functional type are assigned priors and estimated from the data within our Bayesian 163 framework. Saturating functions of irradiance and nitrogen concentration and their 164 combination with a minimum function are commonly used to moderate growth rate 165 (Denman \& Peña 1999, Healey et al. 2009). The net growth rate $\mu_{i}>0$ is the density166 independent growth rate of the $i^{\text {th }}$ functional type at optimal temperature, irradiance and 167 nitrogen concentration. The effects of irradiance and nitrogen concentration on the growth 168 rate are represented by saturating functions parameterized by the half-saturation 169 constants $k_{\mathrm{E}, \mathrm{i}}>0$ and $k_{\mathrm{N}, \mathrm{i}}>0$ which are respectively the irradiance level and nitrogen 170 concentration at which the net growth rate at optimal temperature drops to $\mu_{i} / 2$. The 171 Michaelis-Menten saturating functions are combined with a minimum function so that only 172 the most limiting resource affects growth rate at a time, according to Liebig's law of the 173 minimum (van der Ploeg \& Kirkham 1999). During model development, we explored the 174 possibility of a multiplicative interaction between light and nutrients, but found the results 175 to be more difficult to interpret.

176 To accommodate density-dependent factors including grazing, viral attack, 177 aggregation and sinking, we introduce density dependent loss terms. In the absence of 178 direct observations of these losses, we parameterize the density-dependent losses with $\alpha_{i}$ 
179 and $\phi_{i}$ to quantify the feedbacks on the growth rate of the $i^{\text {th }}$ functional type from its own

180 biomass and from the combined biomass of the other functional types in the community, 181 respectively. The terms involving $\alpha_{i}$ and $\phi_{i}$ distinguish two different density-dependent 182 loss terms, which could result from specialist and generalist grazer populations. For the 183 purposes of estimating the parameters in the model, we rewrote Eq. (1) on the natural 184 logarithmic scale as

$185 y_{w}=y_{w-1}+\mu_{i} \min \left(\frac{P A R_{w-1}}{k_{E, i}+P A R_{w-1}}, \frac{N_{w-1}}{k_{N, i}+N_{w-1}}\right)-\beta_{i}\left|T_{w-1}-\theta_{i}\right|+\alpha_{i} y_{i, w-1}+\phi_{i} z_{i, w-1}+\varepsilon_{i, w}$

187 where $y_{i, w}=\log \left(Y_{i, w}\right), z_{\mathrm{i}, \mathrm{w}}=\log \left(Z_{\mathrm{i}, \mathrm{w}}\right)$ and $\varepsilon_{i, w}=\log \left(\eta_{i, w}\right) \sim N\left(0, \sigma_{i, w}^{2}\right)$.

188 We adapted the functional-type level model described above to define traits at the 189 species level. This task was challenging for two reasons: the greatly increased number of 190 parameters to be estimated and the fact that most species are absent from the time series 191 for most of the time, either because they were absent or their abundance was below the 192 detection limit. By contrast, missing values were rare in the time series of functional type 193 biomasses. We restricted the species-level analysis to the 10 diatoms that were observed in 194 about half of the sampling occasions or more. These species may not be representative of 195 the functional type dynamics as a whole because the selected species only represent $11 \%$ 196 of the diatom functional type biomass. In order to estimate a growth rate, biomass 197 observations for any particular species must be available on numerous pairs of successive 198 weeks. We extracted pairs of observations from the full time series to estimate the growth 199 rate from week $w$-1 to $w$, conditioned on the species being observed during week $w$-1. The 200 species-level model differed from Eqns. (1-3) only in the definition of the biomass terms $201 Y_{i, w}$ and $Z_{i, w}$ and the interpretation of the density-dependent terms $\alpha$ and $\phi$. To emphasize 202 the differences between the functional type and species-level models, we have added a 203 superscript $S$ to the notation for each trait in the species-level model. In the species model, $204 Y_{i, w}$ was the biomass of species $i$ in week $w$, and $Z_{i, w}$ was the sum of the biomass of all 205 species in the same functional type as species $i$ except for species $i$ in week $w$. The densitydependent parameter $\alpha$ reflected the effect of species $i$ on itself while $\phi$ described the 
density-dependent loss due to all species in the same functional type as species $i$ except for species $i$.

The model was developed and fit to the data with a Bayesian approach (Gelman et al. 2013). Bayesian inference is an approach to statistical inference where all unknown

211 quantities are considered as random variables. The uncertainty about plausible values of

212 an unknown quantity $\theta$ before the data is taken into consideration is represented by a

213 probability distribution $p(\theta)$ called the prior distribution. Upon observing the data, the

214 prior distribution is combined with the likelihood function (the sampling distribution of

215 the data) $p(y \mid \theta)$ through Bayes' rule to produce a posterior distribution $p(\theta \mid y)$

$$
p(\theta \mid y)=\frac{p(y \mid \theta) p(\theta)}{p(y)},
$$

where $p(y)=\int_{\Theta} p(y \mid \theta) p(\theta) d \theta$ is the marginal distribution of the data which is the normalizing constant making $p(\theta \mid y)$ a proper probability distribution. Therefore, Eq. (4) can be written as

$$
p(\theta \mid y) \propto p(y \mid \theta) p(\theta) .
$$

where $\propto$ stands for "proportional to".

The posterior distribution represents the data-updated knowledge and forms the basis of Bayesian inference about unknown quantities including model parameters, missing values, and yet unseen data. Having an entire distribution rather than point estimates

229 statements based on the posterior distribution. All Bayesian computations are based on

230 probability rules, resulting in more intuitive statements than counterparts in classical 231 statistics.

232 The hierarchical priors in the Bayesian model allowed us to specify a model with 233 many traits for many functional types or taxonomic units without risking over-fitting the 234 data or running into convergence problems that plague other nonlinear optimization 235 methods. The shared hyper-priors effectively pooled data across taxa when there are few 236 data while allowing trait value estimates to be differentiated across taxa when supported

237 by the data. The model fitting to the functional type biomass data was based on the 238 following essentially non-informative prior distributions for the model parameters. 
$k_{E, i} \sim \mathrm{N}(0,100) \mathrm{I}\left(k_{E, i}>0\right)$, where $\mathrm{I}($.$) denotes the indicator function which takes the value 1$

240 when its argument is true and the value 0 otherwise, $k_{N, i} \sim \mathrm{N}(0,10) \mathrm{I}\left(k_{N, i}>0\right)$,

$241 \beta_{i} \sim \mathrm{N}(0,1) \mathrm{I}\left(\beta_{i}>0\right), \theta_{i} \sim \mathrm{N}(\bar{T}, 10)$, where $\bar{T}$ is the mean temperature over the study period,

$242 \alpha_{i} \sim \mathrm{N}(0,1), \phi_{i} \sim \mathrm{N}(0,1), \sigma_{i, w}^{2} \sim \operatorname{InvGamma}(a, b), a \sim \operatorname{Gamma}(1,1)$ and $b \sim \operatorname{Gamma}(1,1)$. We

243 imposed fairly informative Gamma $(5,5)$ priors independently on the net growth rates $\mu_{i}$

244 to enforce identifiability. For the species model, the hierarchical priors were designed to

245 provide identical trait estimates for all species if the data did not oppose this possibility.

246 The main problem of Bayesian inference comes from the difficulty in evaluating

247 integrals like the one in the denominator of Eq. (4). In most practical cases the posterior is

248 not available in closed form so sampling-based algorithms, mostly Markov chain Monte

249 Carlo (MCMC) methods (Gilks 1996) are used to simulate from it and base inferences on

250 the simulated sample. Markov chain Monte Carlo methods indirectly simulate from a

251 distribution $g$ when direct simulation from $g$ is difficult or impossible. The rationale of

252 MCMC sampling is to set up a Markov chain whose stationary distribution is the

253 distribution $g$ of interest, in this case the joint posterior distribution $p(\theta \mid y)$. Consequently,

254 simulation of $\theta^{(1)}, \theta^{(2)}, \ldots$ from the chain yields a series with the property that the marginal

255 density of $\theta^{(j)}$ for large enough $j$ is approximately $g$. In other words, for a large enough

256 "burn-in" period $n, \theta^{(n+1)}, \theta^{(n+2)}, \ldots$ can be regarded as a dependent series with marginal

257 density $g$. Therefore, empirical moments of this series yield approximations of the

258 moments of $g$.

259 We used Markov chain Monte Carlo (MCMC) simulation (Gilks 2005) implemented

260 in OpenBUGS (Thomas et al. 2006) to sample from the joint posterior of the model

261 parameters. We assessed the convergence of the Markov chains through visual inspection

262 of traceplots and autocorrelation functions. We ran three parallel Markov chains starting

263 from dispersed initial values for 60,000 iterations and discarded the first 30,000 samples

264 from each Markov chain as burn-in. We used the remaining 30,000 samples to generate the

265 posterior distributions on our parameters, retaining every $30^{\text {th }}$ sample to reduce the

266 sample autocorrelation. Our results were robust to changes in the range of priors. 


\section{Results}

269 The three environmental drivers of phytoplankton growth rate included in this

270 study (temperature, irradiance, and nitrogen concentration) exhibit strong, regular

271 seasonal oscillations over the seven-year time series (Widdicombe et al. 2010, Mutshinda

272 et al. 2016). The phytoplankton biomass for each of four functional types each exhibit

273 distinctive patterns of intra-annual variation (Fig. 1). Diatoms bloom first, increasing

274 steadily in biomass from day 60 to day 180. Dinoflagellates and coccolithophorids bloom

275 slightly later, reaching a maximum biomass at approximately day 225. The amplitude of

276 dinoflagellate biomass is the greatest across the four types and their sustained maximum

277 growth and loss rates are also the largest. Phytoflagellates have the least inter-annual

278 variability, with two minor biomass peaks at approximately day 110 and day 215 . Our

279 model is able to describe the biomass dynamics, explaining on average between $51 \%$ (for

280 diatoms) and 95\% (for phytoflagellates) of the variation in the biomass of individual

281 functional types. More importantly, the model produces accurate biomass predictions

282 reflected in narrow, relative to the total variation in the data, posterior predictive intervals

283 (Fig 1). There was insufficient temporal resolution in the data to observe short-term

284 acclimation to changing conditions, so our focus remained on steady-state traits similar to

285 those usually used in phytoplankton community models.

287 Functional-type level analysis

288 The maximum net growth rate trait, $\mu_{i}$, is the largest growth rate of functional type

$289 i$ under any irradiance and nutrient conditions, at its optimal temperature for growth, not

290 including density-dependent grazing, but incorporating linear grazing rates. There is

291 substantial variability in the maximum net growth rate between functional types (whiskers

292 on Fig. 2a). As a group, diatoms have the largest net growth rate with median doubling time

2933.9 days, followed by dinoflagellate with mean doubling time 5.5 days, and phytoflagellate

294 with mean 6.7 days. Coccolithophores have the lowest net growth rate with median

295 doubling time 8.9 days. 
The estimated optimal temperatures for growth for diatom, dinoflagellate,

297 coccolithophorid, and phytoflagellate biomass are $15^{\circ} \mathrm{C}, 20^{\circ} \mathrm{C}, 19^{\circ} \mathrm{C}$ and $11^{\circ} \mathrm{C}$, respectively,

298 implying that higher temperature conditions would favor dinoflagellate and

299 coccolithophorid biomass accumulation (Fig. 2b). As a group, dinoflagellates are the most

300 responsive to temperature changes with a sensitivity parameter roughly twice as large as

301 those of diatoms and coccolithophorids (Fig. 2c). On the other hand, the phytoflagellate

302 biomass is essentially insensitive to temperature changes at Station L4.

303 The nitrogen (nitrate, nitrite, plus ammonia) half-saturation constants, $k_{\mathrm{N}}$, for all

304 groups are comparable to those found in lab studies and used in models (Fig. 2d). The

305 phytoflagellates have the smallest half-saturation constants for irradiance, which is

306 consistent with their relatively small amplitude of biomass variation over the time series.

307 The half-saturation constants for irradiance are not credibly different from one another for

308 the other three phytoplankton functional types and exhibit variability of two-fold or more

309 within their 95\% credible intervals (Fig. 2e). The half-saturation constants for nitrogen

310 concentration (posterior means ranging from $0.02-0.3 \mu \mathrm{mol} \mathrm{L}^{-1}$ ) are quite close to the

311 minimum values of the corresponding environmental data observed over the time-series

$312(0-15 \mu \mathrm{mol} \mathrm{L}-1)$, which suggests that this trait may not be particularly informative for

313 predicting the growth rate of these functional types at this location for most of the year.

314 Conversely, the half-saturating constants for sea-surface irradiance $\left(10-30 \mathrm{~mol} \mathrm{~m}^{-2} \mathrm{~d}^{-1}\right)$

315 span most of the lower half of the inter-annual variation in irradiance (10-50 $\left.\mathrm{mol} \mathrm{m}^{-2} \mathrm{~d}^{-1}\right)$,

316 indicating that phytoplankton growth rates vary with irradiance (light is sub-saturating)

317 for much of the year (Fig. 2e).

318 All four phytoplankton functional types are affected by density-dependent loss rates

319 (Fig. 2f). These losses have the largest effect at high biomass concentrations and can

320 explain the maximum biomass concentration for each functional type, but they are also

321 active at low biomass concentrations and these loss terms are responsible for decreases in

322 biomass when growth conditions are unfavorable. Density-dependent losses are a

323 combination of grazing, viral attack, and aggregation and sinking following bloom collapse.

324 For each functional type, we distinguished between density-dependent feedback due to the

325 functional type's own biomass $(\alpha)$ and the feedback due to the aggregate biomass of all the

326 other functional types $(\phi)$. If the density-dependent loss terms are primarily due to grazing, 
327 we could interpret $\alpha$ as representing losses due to grazers specializing on one functional

328 type and $\phi$ as representing losses due to generalist grazers supported by populations of the 329 other functional types. Since $\alpha<0$ for all functional types, but $\phi$ is not different from 0 for 330 all types, the biomass of each functional type is largely regulated by specialist grazers and 331 generalist grazers have weak density-dependent effects.

Species-level analysis

334 Diatom species' net growth rates were smaller than the functional type counterpart

335 for all ten species examined (Fig. 3a). At the functional-type level, diatoms were weakly

336 affected by temperature $\left(\beta<0.1\right.$ week $\left.^{-1}{ }^{\circ} \mathrm{C}^{-1}\right)$ and this result carried through for the diatom

337 species (most $\beta^{\text {S }}$ close to 0.1 , Fig. 3b). The optimal temperatures were extrapolated outside

338 the range of observed temperatures, and thus are very uncertain (data not shown). Diatom

339 species' half-saturation constants for irradiance are lower than the functional type

340 counterpart whereas diatom species' nitrogen half-saturation constants are higher than the

341 functional type level estimate.

$342 \quad$ For the species model, the density dependent loss analysis was redesigned to

343 identify species-specific density-dependent loss rates and generic functional type density-

344 dependent loss rates. The posterior distributions of the species-level density dependent

345 parameters $\alpha^{S}$ and $\phi^{S}$ imply a stronger negative feedback on each diatom species' biomass

346 growth from its own biomass than that from the combined biomass of other diatom species

347 i.e., $\alpha^{s}<\phi^{s}(\text { Fig. 3e) })^{S}$ ), consistent with niche differentiation within functional types

348 (Mutshinda \& $\mathrm{O}^{\prime}$ Hara 2011). Some of the $\alpha^{S}$ and $\phi^{S}$ for diatoms were positive, suggesting

349 the presence of mutually beneficial or commensal effects in some species.

\section{Discussion}

352 Trait-based models of phytoplankton productivity promise to deliver robust

353 projections of phytoplankton community dynamics under future climate scenarios.

354 Phytoplankton traits are estimated in the lab one species at a time but are commonly

355 aggregated into functional types for ocean biogeochemical models (Anderson 2005, Le

356 Quéré et al. 2005, Litchman et al. 2006). There are several challenges that arise in the 
357 estimates of phytoplankton traits for trait-based models. Most species in diverse

358 communities have not been systematically studied in the lab. Trait values vary across

359 species, even within functional types, and it is not clear how to produce an average trait

360 value for modeling functional types. In addition, there is considerable phenotypic plasticity

361 in traits. Furthermore, grazing rates, viral and parasitic loss rates, sinking rates and biotic

362 interactions, such as allelopathy or mutualisms, can be complex and highly variable from

363 species to species. It is difficult to get good estimates of loss terms, such as grazing rate and

364 viral lysis, that are inherently species specific and patchy in time and space, and we are just

365 starting to learn about the consequences of the many, complex biotic interactions between

366 phytoplankton and their microbial communities (Sher et al. 2011, Amin et al. 2015). It may

367 be possible to overcome some of these myriad challenges using phytoplankton traits

368 estimated directly from field data or by combining lab-based traits with niches estimated

369 from the field (Edwards 2016). Here we extract functional-type and species-level

370 phytoplankton traits from time-series data from a well-studied coastal temperate

371 phytoplankton community in the Western English Channel (Harris 2010, Widdicombe et al.

372 2010). While some of the traits estimated here are consistent with laboratory estimates of

373 similar traits on single species in the lab, many are not, indicating more work is needed to

374 understand how phytoplankton respond in natural communities.

375 Our estimates of maximum net growth rate for the phytoplankton functional types

376 range from 0.4 to 1.5 week $^{-1}$ (a doubling time of 3.2 to 12 days) and for 10 individual

377 diatom species from 0.99 to 1.57 week $^{-1}$ (a doubling time of 6.9 to 11 days). Our growth

378 rate estimates are considerably lower than lab-based estimates of growth rate from

379 unialgal cultures and in situ field estimates of growth rate of individual species (grazers

380 excluded) that can double more than once a day (Furnas 1990, 1991, Raven et al. 2005).

381 Maximum in situ growth rates for three of our ten diatom species have been estimated from

382 daily counts during April in the Irish Sea: Pseudo-nitzchia sp., $0.24 \mathrm{~d}^{-1}$; Guinardia delicatula,

$3830.18 \mathrm{~d}^{-1}$; Lauderia annulata $1.42 \mathrm{~d}^{-1}$. These rates range from approximately the same to up

384 to 25 times our estimated maximum net growth rates (McKinney et al. 1997). Weekly

385 counts, used in our study, are likely to lead to smaller maximum net growth rates than daily

386 counts because the coupling between growth and loss processes will be tighter when

387 averaged over a week instead of a day. We expect our estimate of maximum growth rate to 
388 be lower than traditional estimates of individual species growth rates in the lab and field 389 because our growth rate estimates include linear loss terms due to grazing, viral and 390 parasitic loss and are therefore similar to a net phytoplankton community growth rate.

391 Our values for net growth rate are consistent with satellite-based estimates of monthly 392 median phytoplankton growth rates in temperate regions with strong seasonal blooms, 3930.35 to 4.2 week $^{-1}$ (Westberry et al. 2008). Microzooplankton grazing at Station L4 and 394 elsewhere has been estimated to account for about two-thirds of phytoplankton growth 395 (Fileman et al. 2002, Calbet \& Landry 2004, Chen et al. 2009, Bernard et al. 2012). Given 396 our estimates of maximum growth rates tend to be more than an order of magnitude lower 397 than estimates of growth rate from lab studies, this suggests loss rates due to grazing and 398 parasitoid and viral attack may be higher than often assumed.

399 It would be plausible for there to be no relationship between our field based 400 estimates of maximum growth rates across the functional types even if there are 401 differences in maximum net growth rate since the grazing and other linear loss terms 402 represent such a large fraction of maximum net growth rate. We find the rank order in our 403 estimates of net growth rates for the functional types (diatoms > dinoflagellates $>$ 404 phytoflagellates $>$ coccolithophorids) are generally consistent with growth rates reported 405 from laboratory culture work and field observations (Furnas 1991, Cermeño et al. 2005, 406 Raven et al. 2005, Laws 2013). In the Western English Channel we find diatoms have the 407 largest maximum net growth rate, which is roughly double that of coccolithophorids and 408 phytoflagellates (Fig. 2a). These results indicate that lab-based maximum growth rates 409 combined with a constant loss rate used by many models may be a reasonable proxy for net 410 growth rates in natural communities.

411 The effect of temperature on phytoplankton species growth rates is commonly 412 described using the $\mathrm{Q}_{10}$ approximation, which is the multiplicative effect of a $10^{\circ} \mathrm{C}$ change 413 in temperature on growth rate. This value is typically about 2 , ranging from 1.88 to 2.3 for 414 phytoplankton (Eppley 1972, Bissinger et al. 2008). The range of temperatures at Station $415 \mathrm{~L} 4$ (about $8-18^{\circ} \mathrm{C}$ ) is narrow compared to the width of many phytoplankton temperature 416 niches (Irwin et al. 2012, Boyd et al. 2013) so we used a linear model to describe the effect 417 of temperature on growth rate (see Montagnes et al. 2003 for additional rationale for using 418 a linear model). The temperature sensitivity of the functional types, $\beta$, is about 0.11 week $^{-1}$ 
$419{ }^{\circ} \mathrm{C}^{-1}$ for dinoflagellates, 0.06 week $^{-1}{ }^{\circ} \mathrm{C}^{-1}$ for coccolithophorids and 0.05 week ${ }^{-1}{ }^{\circ} \mathrm{C}^{-1}$ for 420 diatoms, meaning that growth rate would increase from roughly 1 week $^{-1}$ to 1.7 week $^{-1}$ for

421 dinoflagellates, from 1 week $^{-1}$ to 1.4 week $^{-1}$ for coccolithophorids, and from 1 week ${ }^{-1}$ to 1.3

422 week $^{-1}$ for diatoms with an increase in temperature of $6^{\circ} \mathrm{C}$ (half the annual amplitude in

423 temperature) starting below their temperature optimum (Fig. 2c). Analysis of the change in

424 maximum growth rate with temperature from unialgal lab cultures (Montagnes et al. 2003)

425 found a slope 0.11 to 0.54 week $^{-1}{ }^{\circ} \mathrm{C}^{-1}$ for dinoflagellates, which is comparable to the

426 posterior means ( 0.11 week $\left.^{-1}{ }^{\circ} \mathrm{C}^{-1}\right)$ found in this study (Fig. 2c), and 0.084 to 0.97 week $^{-1}{ }^{\circ} \mathrm{C}^{-}$

$427{ }^{1}$ for diatoms which is higher than the posterior mean $\left(0.055\right.$ week $\left.^{-1}{ }^{\circ} \mathrm{C}^{-1}\right)$ found in this

428 study. For phytoflagellates our temperature trait $\beta$ is 0.017 week ${ }^{-1}{ }^{\circ} \mathrm{C}^{-1}$ which is close to

429 zero and the credible interval is narrow and close to 0 , so we conclude that temperature

430 has essentially no effect on the growth rate of this functional type at this site. Possible

431 interpretations for this result are that the phytoflagellates have broad temperature optima

432 for growth rate or the functional type is composed of many species with specialized

433 optimal growth temperatures spread across the range of observed temperatures (Eppley

434 1972, Boyd et al. 2013). This does not appear to be the case for dinoflagellates and

435 coccolithophorids; even if there is species turnover during the year, there is still a strong

436 imprint of temperature on the growth rate of the functional type as a whole. An alternative

437 explanation is that an increase in water column stability favors an increase in dinoflagellate

438 and coccolithophorid biomass accumulation (Margalef 1978, 1997). The optimal

439 temperature for growth at the functional type level varies as expected with diatoms and

440 phytoflagellates having lower optimal temperatures than dinoflagellates and

441 coccolithophorids, which bloom later in the season. Since temperature is correlated with

442 stability and we don't have an independent measure of stability, our model is unable to

443 distinguish between the direct effects of temperature and the effect of water column

444 stability on the growth rate of phytoplankton.

445 Temperature optima for individual diatom species were not identified within the

446 range of observed temperatures (not shown); we interpreted these results as consistent

447 with wide temperature response curves, relative to the narrow temperature range at

448 Station L4, for each species (Boyd et al. 2013). The estimates of the strength of the

449 temperature effect for individual diatom species ( $\beta^{\text {s }}$, Fig. 3b) was roughly twice as high as 
450 the effect on the diatom functional type. Averaging responses over many species in a

451 functional type could lead to weaker effects of temperature change as contrasting effects of 452 temperature on individual species partially cancel each other out.

453 Light and nutrient limitation of net growth rate is determined by Michaelis-Menten

454 half-saturation trait values, $k_{\mathrm{N}}$ and $k_{\mathrm{E}}$. Three sources of inorganic nitrogen: nitrate, nitrite,

455 and ammonium are considered in our estimate of $k_{\mathrm{N}}$ for inorganic nitrogen. As a result our

456 estimate of $k_{\mathrm{N}}$ at the functional type level is largely determined by the inorganic nitrogen

457 species with the smallest half-saturation constant. Half-saturation constants for nitrogen

458 for phytoplankton species can vary from 0.08 to $8.4 \mu \mathrm{mol} \mathrm{L}^{-1}$ in the lab (Litchman et al.

459 2006). Our half-saturation constants for individual diatom species, many with large cell

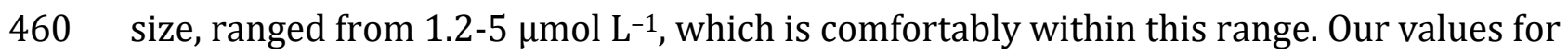

461 functional types range from about 0.02 to $0.22 \mu \mathrm{mol} \mathrm{L}^{-1}$, and are either on the lower end or

462 smaller than typical literature values for unialgal cultures. Diatoms and dinoflagellates as

463 functional types have $k_{\mathrm{N}}$ approximately a factor of ten smaller than many lab-based

464 literature estimates. The half-saturation constants for inorganic nitrogen for the

465 phytoplankton functional types at the site are also low relative to all but the lowest

466 nitrogen concentrations observed in seawater at this site (ranging from 0.1-16 $\mu \mathrm{mol} \mathrm{L}^{-1}$,

467 only $10 \%$ of observations are less than $0.20 \mu \mathrm{mol} \mathrm{L}^{-1}$ ), indicating that nitrogen limitation is

468 only a significant factor affecting growth rates of functional types, particularly diatoms and

469 dinoflagellates, in the warmest part of the summer. One reason $k_{\mathrm{N}}$ may be lower in the field

470 relative to laboratory studies is that organic nitrogen may be an important source of

471 nitrogen for some species, particularly the dinoflagellates and phytoflagellates, but also

472 some diatoms such as Pseudo-nitzschia delicatissima (Loureiro et al. 2009). If organic

473 sources are important for these groups, for example following the crash of a diatom bloom

474 when inorganic nitrogen concentrations are low, estimated $k_{\mathrm{N}}$ may be artificially low since

475 organic sources were not included in the model. Alternatively, since nitrogen is taken up

476 rapidly when available, bulk estimates of reactive nitrogen concentration sampled weekly

477 may be relatively uninformative at physiological scales (Laws 2013). The phytoflagellates

478 have the lowest $k_{\mathrm{N}}$ of approximately $0.02 \mu \mathrm{mol} \mathrm{L}-1$, which is less than half the value for

479 diatoms and roughly $10 \%$ of the value of coccolithophorids (Fig. $2 \mathrm{~d}$ ). The phytoflagellate

480 category is taxonomically diverse, but over half the biomass is found in unidentified cells 
481 smaller than $5 \mu \mathrm{m}$ in diameter. The resulting high surface area to volume ratio is consistent 482 with very low $k_{\mathrm{N}}$ (Fiksen et al. 2013). The most significant feature of our results is that the 483 phytoplankton dynamics at Station L4 is consistent with very low $k_{\mathrm{N}}$ compared to values 484 estimated from laboratory cultures (Litchman et al. 2007). The $k_{\mathrm{N}}$ at Station L4 are 5-10 485 fold smaller than half-saturation constants for nitrate often employed in ecosystem models 486 (Gregg et al. 2003, Merico et al. 2004). The intermediate complexity marine ecosystem 487 model constructed by Moore et al (2002) is an exception; this model uses a very low $k_{\mathrm{N}}$ for 488 ammonium of $0.004 \mu \mathrm{mol} \mathrm{L} \mathrm{L}^{-1}$ for small cells, much lower than our values for Station L4 489 (Moore et al. 2002). Generally $k_{\mathrm{N}}$ for ammonium are smaller than values for nitrate 490 (Litchman et al. 2007; Merico et al. 2004).

491 Light limitation is frequently parameterized by a half-saturation coefficient, $k_{\mathrm{E}}$, or 492 the irradiance at which light saturates growth, $E_{\mathrm{k}}$. For comparison between the two, we 493 divide $E_{\mathrm{k}}$ by 2 to roughly approximate $k_{\mathrm{E}}$. In natural populations in coastal regions, $E_{\mathrm{k}}$ 494 varies from $40-500 \mu \mathrm{mol} \mathrm{m}^{-2} \mathrm{~s}^{-1}$ (Kirk 2010), corresponding to $k_{\mathrm{E}}$ of about 2-22 $\mathrm{mol} \mathrm{m}^{-2} \mathrm{~d}^{-}$ 495 1. Estimates of $k_{\mathrm{E}}$ in unialgal cultures range from 3.5-7.8 $\mathrm{mol} \mathrm{m}^{-2} \mathrm{~d}^{-1}$ (Litchman et al. 2006), 496 and varies with steady state irradiance (Gregg et al. 2003, Kirk 2010). At Station L4, our 497 values of $k_{\mathrm{E}}$ range from 8 to $20 \mathrm{~mol} \mathrm{~m}^{-2} \mathrm{~d}^{-1}$, but these are based on sea-surface irradiance 498 and thus are larger than they would be based on average in situ irradiances. Individual 499 diatom species have $k_{\mathrm{E}}$ ranging from 6-14 $\mathrm{mol} \mathrm{m}^{-2} \mathrm{~d}^{-1}$, closer to the values for unialgal 500 cultures. These results suggest that irradiance at Station L4 is limiting for diatoms, 501 dinoflagellates and coccolithophorids during much of the year, since sea-surface PAR 502 ranges from $10-50 \mathrm{~mol} \mathrm{~m}^{-2} \mathrm{~d}^{-1}$ and only exceeds $E_{\mathrm{k}} \cong 2 k_{\mathrm{E}} \cong 40 \mathrm{~mol} \mathrm{~m}^{-2} \mathrm{~d}^{-1}$ for these groups 503 during short periods in the summer. By contrast, phytoflagellates have $k_{\mathrm{E}}$ near the 504 minimum levels of PAR and so they experience saturating irradiance for most of the year.

505 One possible hypothesis is that their small size confers a low pigment package effect, 506 meaning they have high light absorption per unit of pigment, giving them an advantage 507 over functional types with larger cells under low light conditions (Finkel \& Irwin 2000, 508 Finkel 2001, Finkel et al. 2004). Furthermore, if some of the phytoflagellates use alternative 509 energy sources, they may require less chlorophyll and be less sensitive to changes 510 irradiance. While some dinoflagellates are known to be heterotrophic and mixotrophic 511 (Stoecker 1999), unlike phytoflagellates their growth rate is strongly affected by low 
512 temperatures in winter, reducing their growth rate in winter relative to phytoflagellates

513 (Fig. 1). Phytoflagellates appear to be able to acclimate to very low light, giving them a

514 competitive advantage relative to the other functional types, especially in winter.

$515 \quad$ Many studies of zooplankton grazing focus on the linear grazing rate (Landry \&

516 Hassett 1982, Calbet \& Landry 2004, Zheng et al. 2015), which in our model is combined

517 with gross phytoplankton growth rate to obtain the maximum net growth rate trait, $\mu$,

518 which is a constant for each phytoplankton functional type. More complex formulations of

519 zooplankton grazing rates permit diel and seasonal variation in grazing rates and non-

520 linear grazing rates (Tsai et al. 2005) or describe prey switching or selectivity by grazers

521 (Gentleman et al. 2003, Vallina et al. 2014), but we do not consider these mechanisms. Our

522 model incorporates density-dependent loss terms to describe consumption of

523 phytoplankton by grazers along with other loss processes. All four functional types exhibit

524 strong density-dependent loss. Assuming the loss term is primarily attributable to grazing,

525 diatoms and phytoflagellates are primarily grazed by specialists $(\alpha<0$, Fig. 2$)$ and

526 unaffected by generalist grazers $(\phi \cong 0)$ while dinoflagellates and coccolithophorids were

527 roughly equally affected by specialist generalist grazers $(\phi \cong \alpha)$. The difference between

528 specialist and generalist density-dependent losses is evidence of strong niche

529 differentiation for diatoms and phytoflagellates. The results at the species level are more

530 variable. Six of our ten diatom species exhibit positive density-dependent effects $\left(\phi^{S}>0\right.$,

531 Fig. 3c) with increased biomass of all other diatoms, which could be an indication that these

532 species experience less grazing pressure when the biomass of other diatoms is high ("kill

533 the winner") (Vallina et al 2014). Two species, Guinardia delicatula and Pseudo-nitzschia

534 seriata, have positive density-dependent effects resulting from their own biomass $\left(\alpha^{S}>0\right)$,

535 indicating that increases in their biomass can increase their own growth rates. Many

536 strains of Pseudo-nitzschia have been shown to produce the neurotoxin domoic acid (Bates

537 et al. 1998, Fehling et al. 2004), suggesting this positive density-dependence may be a

538 result of allelopathy, although G. delicatula does not produce toxins and Pseudo-nitzschia

539 delicatissima has $\alpha^{S}=0$. Finally, three species have negative density dependence arising

540 from their own biomass $\left(\alpha^{S}<0\right)$. Nitzschia closterium is known to produce mucus that may

541 increase its export at high densities, which is consistent with this result (Najdek et al.

542 2005). 
Our analysis of ten diatom species demonstrates the potential and challenges of this

544 approach for determining trait values and modeling dynamics of individual species. These 545 species were the most frequently observed in the population, but account for only $11 \%$ of 546 the total biomass, on average. Species with fewer observations are less likely to yield 547 informative estimates of trait values due to a lack of data, but account for the vast majority 548 of the biomass. Since our ten species sample is a minority component of the diatom

549 community and represents species present much of the year in contrast to species present 550 for only a few weeks at a time, there is no reason to expect the trait values of these species 551 to be representative of the functional type as a whole. In fact, we observed systematic

552 differences between trait values for these species and the diatom functional type:

553 maximum growth rate is lower and $k_{\mathrm{N}}$ is higher for the all the species analyzed relative to

554 the functional type. Even if we had a random sample of species with trait values

555 representative of the full distribution, determining functional-type level trait values by

556 averaging over species with different traits and changing contributions to the total

557 population can lead to errors due to Simpson's paradox (Chuang et al. 2009, Williams \&

558 Hastings 2011). The uncertainties across the diatom species are large enough to suggest

559 that the trait values may be largely indistinguishable across many species (Fig. 3). An

560 independent analysis showed that diatoms species at Station L4 exhibit neutral dynamics

561 within the diatom functional type most of the time, indicating that predicting biomass

562 dynamics of individual species may be much harder than predicting the dynamics of the

563 aggregated biomass of a functional type (Mutshinda et al. 2016). While it is appealing to

564 estimate trait values for functional types from knowledge of individual species, it may be

565 more prudent to deemphasize species-level detail and use realized traits estimated from

566 biomass dynamics aggregated to the functional-type level.

568 Conclusions

569 This study enables a comparative analysis of trait values used in biogeochemical 570 models of phytoplankton communities and the trait values estimated from lab studies on 571 individual phytoplankton. The realized traits we quantified could be different from those 572 estimated in the lab because they are functional-type level aggregates and include factors 573 such as phenotypic plasticity and biotic interactions that may vary across species and 
574 communities. At Station L4 in the Western English Channel, diatoms have the highest

575 maximum net growth rates, low half-saturation constant for nitrogen, a low temperature

576 optimum and low temperature sensitivity, and high specialist density-dependent loss rates.

577 By contrast, the dinoflagellates have intermediate maximum net growth rates, high

578 temperature optima and sensitivity. Coccolithophorids have the lowest maximum net

579 growth rate, high temperature optimum and intermediate temperature sensitivity, high

580 half-saturation constants for nitrogen and light, and like the dinoflagellates show similar

581 rates of specialist and generalist density-dependent losses. The phytoflagellates have low

582 maximum net growth rate, low optimum temperatures and sensitivities, low half-

583 saturation constants, and intermediate levels of specialist density-dependent losses. The

584 relative differences in maximum net growth rate, specifically the relatively high rates for

585 diatoms, are consistent with differences estimated in the lab and the field, but the absolute

586 magnitude of the rates are considerably lower because our maximum growth rates include

587 linear loss terms. A comparison of our results with traits estimated in the lab and used in

588 models yields a few insights. Grazing and other linear loss rates, as reflected in a reduction

589 of the gross growth rate, appear be even more important than usually appreciated. We see

590 evidence of complex biotic interactions that are difficult to assess in the lab: diatoms and

591 phytoflagellates are more susceptible to specialist loss rates, perhaps indicating specialist

592 grazers or viruses. At the species level, there appears to be evidence of species interactions

593 increasing the net growth rate of individual diatom species. The half-saturation constants

594 for nitrogen are considerably lower than typical lab estimates, consistent with the use of a

595 wide range of reactive nitrogen sources and widespread mixotrophy. There is considerable

596 variation in our estimates of the trait values within phytoplankton functional types, which

597 could be due to real physiological changes arising from acclimation to environmental

598 conditions over time, variation across species within a functional type, or a consequence of

599 insufficient data. Time-series of field data combined with our analysis gives us insight into

600 the mechanisms affecting the dynamics of species and whole functional types in natural

601 populations that may improve our ability to scale-up results from species-level studies in

602 the lab to community dynamics in the ocean.

603

604 


\section{Acknowledgements}

606 Station L4 phytoplankton biomass and environmental data were provided by the Western 607 Channel Observatory which was funded as part of the UK Natural Environmental Research 608 Council's National Capability. EMS Woodward and C Harris provided the nutrient data. We 609 thank A Atkinson and T Smyth for assistance and advice. ZVF was supported by the 610 National Science and Engineering Research Council (NSERC) of Canada and the Canada 611 Research Chairs program. AJI was supported by NSERC.

612

613 
614

615 Figure 1.

616 Observed (black line) and predicted (shaded region) $\log _{10}$ carbon biomass $\left(\mathrm{mg} \mathrm{C} \mathrm{m}^{-3}\right.$ ) of

617 each functional type (diatoms, dinoflagellates, coccolithophorids, and phytoflagellates) at

618 Station L4. The prediction region is the 95\% credible range of biomass from the functional 619 type model.

620 


\section{Figure 1.}

622
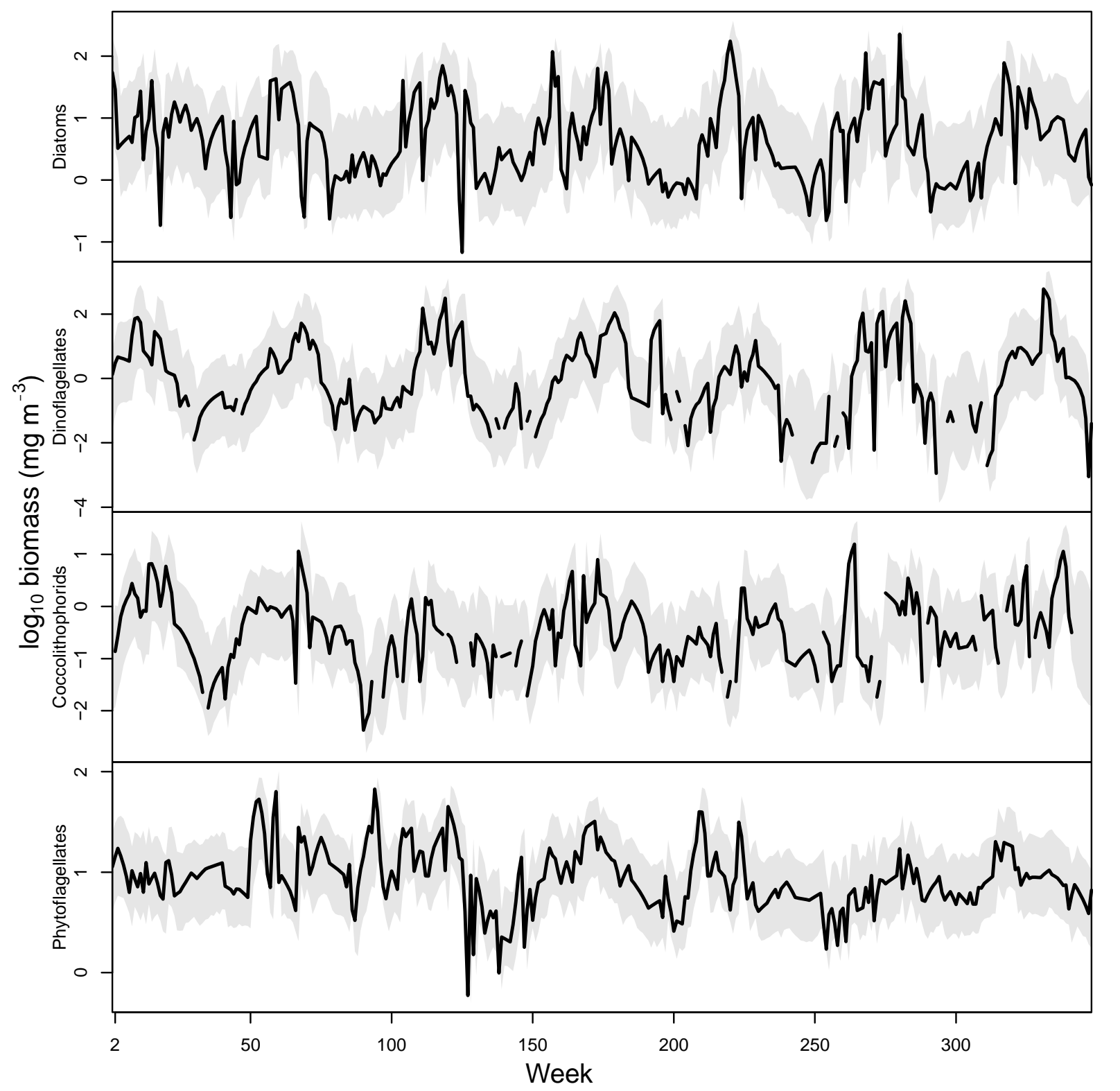

623

624 


\section{Figure 2.}

627 Posterior distributions of traits governing growth rate at the functional type level. (a)

628 Maximum net growth rate, $\mu\left(\right.$ week $\left.^{-1}\right),(\mathrm{b})$ the optimal temperature $\theta\left({ }^{\circ} \mathrm{C}\right),(\mathrm{c})$ temperature

629 sensitivity, $\beta$ (week ${ }^{-1}{ }^{\circ} \mathrm{C}^{-1}$ ), (d) the half-saturation constants for nitrogen, $k_{\mathrm{N}}\left(\mu \mathrm{mol} \mathrm{L} \mathrm{L}^{-1}\right.$ ), (e)

630 the half-saturation constants for irradiance, $k_{\mathrm{E}}\left(\mathrm{mol} \mathrm{m}^{-2} \mathrm{~d}^{-1}\right)$, and (f) density-dependent

631 effects on the growth rate of each functional type attributed to their own biomass $(\alpha$, solid

632 circle) and to the total biomass of the other functional types in the community ( $\phi$, open

633 circle). Box plots show median (thick line), the interquartile range (box) and the full range

634 of the data or 1.5 times the interquartile range, whichever is smaller (whiskers). In panels

635 (c) and (f) error bars indicate 95\% credible intervals on the posterior means and are used 636 because posterior distribution are approximately normal. In (f), the horizontal dashed line 637 indicates no density-dependence. The vertical scale in (d) is logarithmic to facilitate the 638 display of the wide range of values. 
$640 \quad$ Figure 2.

641
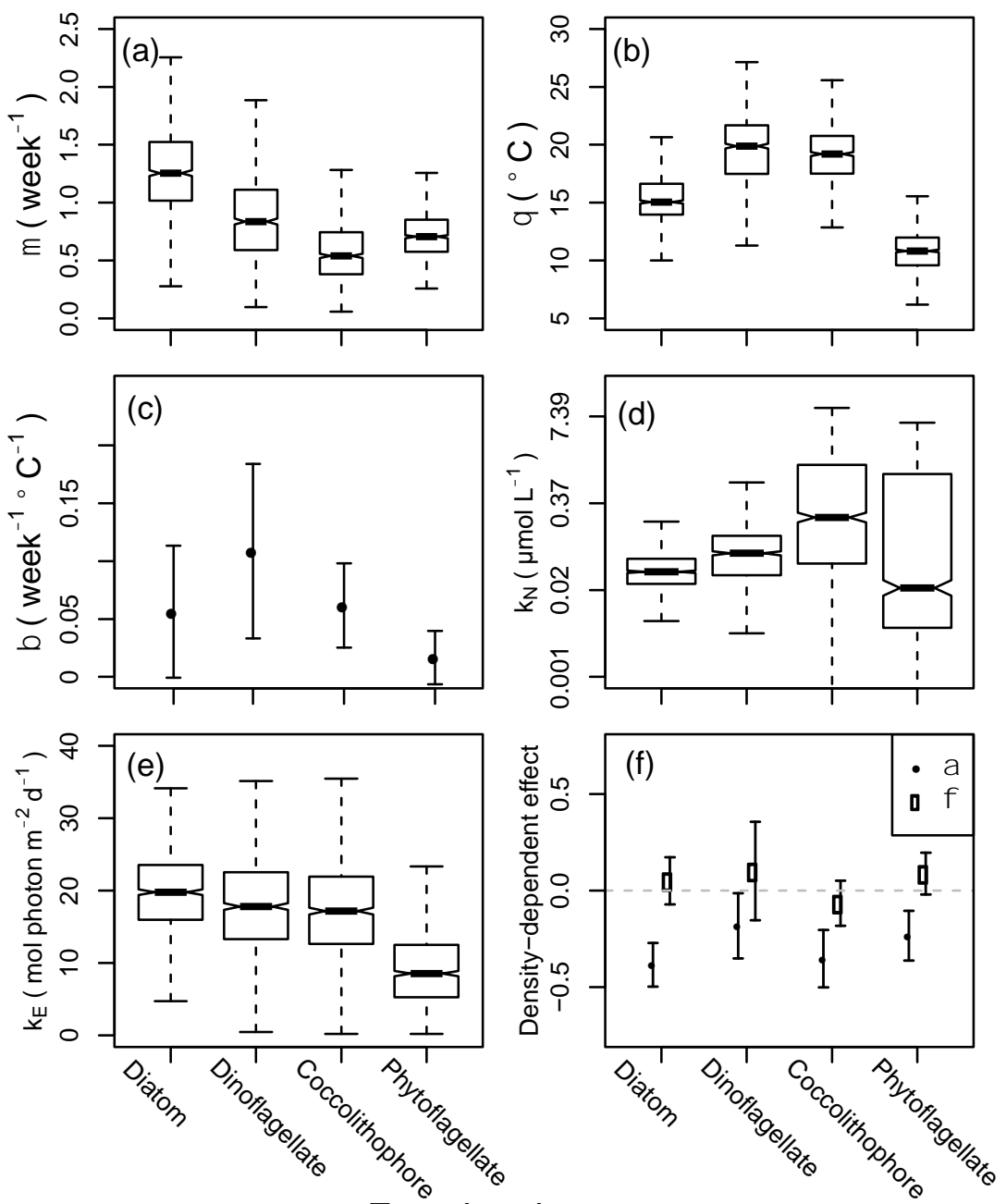

642

Functional type 


\section{$643 \quad$ Figure 3.}

644 Species-level trait values for ten diatom species. Species are arranged in order of the 645 number of weeks they are present in the time-series from Nitzschia closterium (93\% of 646 weeks) to Lauderia annulata (48\%). (a) Maximum net growth rate, $\mu^{S}$ (week ${ }^{-1}$ ), (b) 647 temperature sensitivity, $\beta^{S}$ (week ${ }^{-1}{ }^{\circ} \mathrm{C}^{-1}$ ), (c) the half-saturation constants for nitrogen, $k_{\mathrm{N}} \mathrm{S}$ $648\left(\mu \mathrm{mol} \mathrm{L}^{-1}\right),(\mathrm{d})$ the half-saturation constants for irradiance, $k_{\mathrm{E}}^{\mathrm{S}}\left(\mathrm{mol} \mathrm{m}^{-2} \mathrm{~d}^{-1}\right)$, and (e) 649 density-dependent effects on the growth rate of each functional type attributed to their 650 own biomass ( $\alpha^{S}$, solid circle) and to the total biomass of the other functional types in the 651 community ( $\phi^{S}$, open circle). Box plots show median (thick line), the interquartile range 652 (box) and the full range of the data or 1.5 times the interquartile range, whichever is 653 smaller (whiskers). In panels (b) and (e) error bars indicate 95\% credible intervals on the 654 posterior means and are used because posterior distribution are approximately normal. In 655 (e), the horizontal dashed line indicates no density-dependence. The vertical scale in (c) is 656 logarithmic to facilitate the display of the wide range of values. 
Figure 3.

659
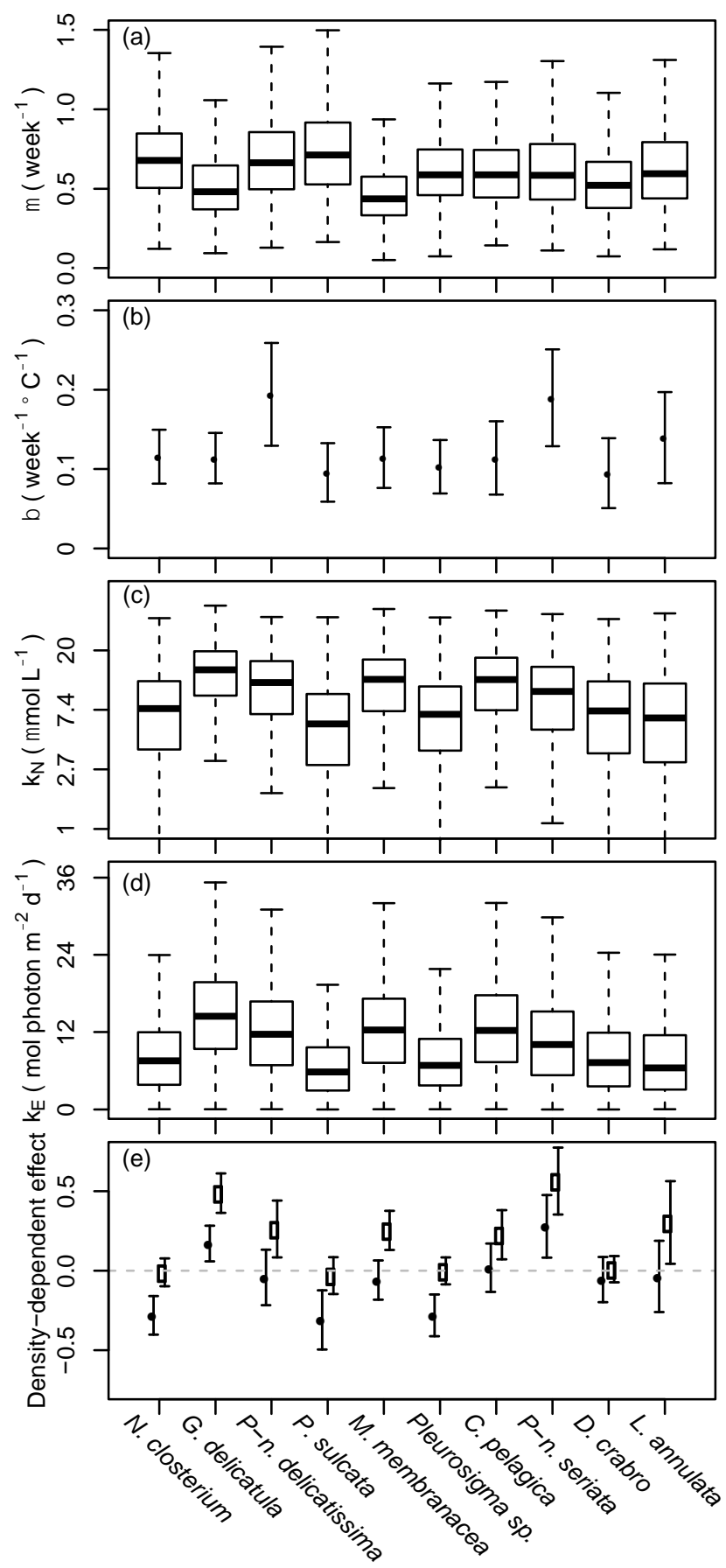

660 


\section{Table 1.}

662 Key symbols for data and traits in the models. Traits for diatom species (as opposed to 663 functional types) have a superscript $S$ added.

664

\begin{tabular}{lll} 
Symbol & Units & Interpretation \\
\hline$Y_{\mathrm{i}}, y_{\mathrm{i}}$ & $\mathrm{mg} \mathrm{C} \mathrm{m}^{-3}$ & Biomass, log biomass of functional types or species in week $i$ \\
$T_{\mathrm{i}}$ & ${ }^{\circ} \mathrm{C}$ & Temperature in week $i$ \\
$N_{\mathrm{i}}$ & $\mathrm{mg} \mathrm{N} \mathrm{m}^{-3}$ & Total inorganic N in week $i$ \\
$P A R_{\mathrm{i}}$ & $\mathrm{mol} \mathrm{m}^{-2} \mathrm{~d}^{-1}$ & Sea-surface irradiance in week $i$ \\
$\mu, \mu^{\mathrm{S}}$ & week $^{-1}$ & Maximum net growth rate for a functional type, species \\
$r, r^{\mathrm{S}}$ & week $^{-1}$ & Realized net growth rate for a functional type, species \\
$k_{\mathrm{N}}, k_{\mathrm{N}} \mathrm{S}$ & $\mathrm{mg} \mathrm{N} \mathrm{m}^{-3}$ & Half-saturation constant for growth as a function of N \\
& & concentration \\
$k_{\mathrm{E}}, k_{\mathrm{E}} \mathrm{S}$ & $\mathrm{mol} \mathrm{m}^{-2} \mathrm{~d}^{-1}$ & Half-saturation constant for growth as a function of \\
& & irradiance \\
$\beta, \beta^{\mathrm{S}}$ & week ${ }^{-1} \mathrm{C}^{-1}$ & Magnitude of linear increase in net growth rate with \\
& & temperature, temperature sensitivity \\
$\theta, \theta^{\mathrm{S}}$ & ${ }^{\circ} \mathrm{C}$ & Temperature with maximum growth rate \\
$\alpha, \alpha^{\mathrm{S}}$ & & Density dependent loss coefficient within functional type, \\
& & diatom species \\
& & Density dependent loss coefficient due to other functional \\
& & types, other diatom species
\end{tabular}

665

666 


\section{Literature cited}

669

670

671

672

673

674

675

676

677

678

679

680

681

682

683

684

685

686

687

688

689

690

691

692

693

694

695

696

697

698

699

700

701

702

703

704

705

706

707

708

709

710

711

712

Amin S, Hmelo L, van Tol H, Durham B, Carlson L, Heal K, Morales R, Berthiaume C, Parker M, Djunaedi B (2015) Interaction and signalling between a cosmopolitan phytoplankton and associated bacteria. Nature 522:98-101

Anderson TR (2005) Plankton functional type modelling: running before we can walk? J Plankton Res 27:1073-1081

Bates SS, Garrison DL, Horner RA (1998) Bloom dynamics and physiology of domoic-acidproducing Pseudo-nitzschia species. NATO ASI series G ecological sciences 41:267292

Bernard KS, Steinberg DK, Schofield OM (2012) Summertime grazing impact of the dominant macrozooplankton off the Western Antarctic Peninsula. Deep Sea Research Part I: Oceanographic Research Papers 62:111-122

Bissinger JE, Montagnes DJS, Sharples J, Atkinson D (2008) Predicting marine phytoplankton maximum growth rates from temperature: improving on the Eppley curve using quantile regression. Limnol Oceanogr 53:487-493

Boyd PW, Rynearson TA, Armstrong EA, Fu F, Hayashi K, Hu Z, Hutchins DA, Kudela RM, Litchman E, Mulholland MR (2013) Marine phytoplankton temperature versus growth responses from polar to tropical waters-outcome of a scientific communitywide study. Plos ONE 8:e63091

Calbet A, Landry MR (2004) Phytoplankton growth, microzooplankton grazing, and carbon cycling in marine systems. Limnol Oceanogr 49:51-57

Cermeño P, Marañón E, Rodríguez J, Fernández E (2005) Large-sized phytoplankton sustain higher carbon-specific photosynthesis than smaller cells in a coastal eutrophic ecosystem. Mar Ecol Prog Ser 297:51-60

Chen B, Liu H, Landry MR, Dai M, Huang B, Sune J (2009) Close coupling between phytoplankton growth and microzooplankton grazing in the western South China Sea. Limnol Oceanogr 54:1084-1097

Chuang JS, Rivoire 0, Leibler S (2009) Simpson's paradox in a synthetic microbial system. Science 323:272-275

Colwell RK, Rangel TF (2009) Hutchinson's duality: the once and future niche. Proc Nat Acad Sci 106:19651-19658

de Vargas C, Audic S, Henry N, Decelle J, Mahé F, Logares R, Lara E, Berney C, Le Bescot N, Probert I, Carmichael M, Poulain J, Romac S, Colin S, Aury J-M, Bittner L, Chaffron S, Dunthorn M, Engelen S, Flegontova O, Guidi L, Horák A, Jaillon O, Lima-Mendez G, Lukeš J, Malviya S, Morard R, Mulot M, Scalco E, Siano R, Vincent F, Zingone A, Dimier C, Picheral M, Searson S, Kandels-Lewis S, Coordinators TO, Acinas SG, Bork P, Bowler C, Gorsky G, Grimsley N, Hingamp P, Iudicone D, Not F, Ogata H, Pesant S, Raes J, Sieracki ME, Speich S, Stemmann L, Sunagawa S, Weissenbach J, Wincker P, Karsenti E (2015) Eukaryotic plankton diversity in the sunlit ocean. Science 348:1261605

Denman KL, Peña MA (1999) A coupled 1-D biological/physical model of the northeast subarctic Pacific Ocean with iron limitation. Deep-Sea Res Part II-Top Stud Oceanogr 46:2877-2908

Edwards KF (2016) Community trait structure in phytoplankton: seasonal dynamics from a method for sparse trait data. Ecology. in press. doi: 10.1002/ecy.1581 
Eppley RW (1972) Temperature and phytoplankton growth in the sea. Fish Bull 70:10631085

Fehling J, Green DH, Davidson K, Bolch CJ, Bates SS (2004) Domoic acid production by Pseudo-nitzschia seriata (Bacillariophyceae) in Scottish waters. J Phycol 40:622-630

Field C, Behrenfeld M, Randerson J, Falkowski P (1998) Primary production of the biosphere: integrating terrestrial and oceanic components. Science 281:237-240

Fiksen $\emptyset$, Follows MJ, Aksnes DL (2013) Trait - based models of nutrient uptake in microbes extend the Michaelis - Menten framework. Limnol Oceanogr 58:193-202

Fileman E, Cummings D, Llewellyn C (2002) Microplankton community structure and the impact of microzooplankton grazing during an Emiliania huxleyi bloom, off the Devon coast. Journal of the Marine Biological Association of the UK 82:359-368

Finkel ZV (2001) Light absorption and size scaling of light-limited metabolism in marine diatoms. Limnol Oceanogr 46:86-94

Finkel ZV (2014) Marine Net Primary Production. Global Environmental Change. Springer

Finkel ZV, Beardall J, Flynn KJ, Quigg A, Rees TAV, Raven JA (2010) Phytoplankton in a changing world: Cell size and elemental stoichiometry. J Plankton Res 32:119-137

Finkel ZV, Irwin AJ (2000) Modeling size-dependent photosynthesis: Light absorption and the allometric rule. Journal of Theoretical Biology 204:361-369

Finkel ZV, Irwin AJ, Schofield 0 (2004) Resource limitation alters the 3/4 size scaling of metabolic rates in phytoplankton. Mar Ecol Prog Ser 273:269-279

Flynn KJ, St John M, Raven JA, Skibinski DO, Allen JI, Mitra A, Hofmann EE (2015) Acclimation, adaptation, traits and trade-offs in plankton functional type models: reconciling terminology for biology and modelling. J Plankton Res 37:683-691

Furnas MJ (1990) In situ growth rates of marine phytoplankton: approaches to measurement, community and species growth rates. J Plankton Res 12:1117-1151

Furnas MJ (1991) Net in situ growth rates of phytoplankton in an oligotrophic, tropical shelf ecosystem. Limnol Oceanogr 36:13-29

Gelman A, Carlin JB, Stern HS, Dunson DB, Vehtari A, Rubin DB (2013) Bayesian data analysis. Chapman and Hall, London, England

Gentleman W, Leising A, Frost B, Strom S, Murray J (2003) Functional responses for zooplankton feeding on multiple resources: a review of assumptions and biological dynamics. Deep Sea Research Part II: Topical Studies in Oceanography 50:28472875

Gilks WR, Richardson S, Spiegelhalter DJ (1996) Markov Chain Monte Carlo in Practice.

Chapman \& Hall, London, England.

Gilks WR (2005) Markov chain monte carlo. Wiley

Gregg WW, Ginoux P, Schopf PS, Casey NW (2003) Phytoplankton and iron: validation of a global three-dimension ocean biogeochemical model. Deep-Sea Res II 50:3143-3169 Grover JP (1991) Non-steady state dynamics of algal population growth: experiments with two chlorophytes. J Phycol 27:70-79

Harris R (2010) The L4 time-series: the first 20 years. J Plankton Res 32:577-583 Healey K, Monahan AH, Ianson D (2009) Perturbation dynamics of a planktonic ecosystem. J Mar Res 67:637-666 
Hood RR, Laws EA, Armstrong RA, Bates NR, Brown CW, Carlson CA, Chai F, Doney SC, Falkowski PG, Feely RA, Friedrichs MAM, M.R. L, Moore JK, Nelson DM, Richardson TL, Salihoglu B, Schartau M, Toole DA, Wiggert JD (2006) Pelagic functional group modelling: progress, challenges and prospects. Deep-Sea Res II 53:459-512

Hutchinson GE (1957) Cold spring harbor symposium on quantitative biology. Concluding remarks 22:415-427

Irwin AJ, Finkel ZV (2016) Phytoplankton functional types: a functional trait perspecitive. In: Kirchman DM, Gasol JM (eds) Microbial ecology of the ocean. Wiley

Irwin AJ, Nelles AM, Finkel ZV (2012) Phytoplankton niches estimated from field data. Limnol Oceanogr 57:787-797

Kirk JT (2010) Light and Photosynthesis in Aquatic Ecosystems. Cambridge University Press

Landry M, Hassett R (1982) Estimating the grazing impact of marine micro-zooplankton. Mar Biol 67:283-288

Laws EA (2013) Evaluation of in situ phytoplankton growth rates: a synthesis of data from varied approaches. Annual review of marine science 5:247-268

Le Quéré C, Harrison SP, Colin Prentice I, Buitenhuis ET, Aumont O, Bopp L, Claustre H, Cotrim Da Cunha L, Geider R, Giraud X (2005) Ecosystem dynamics based on plankton functional types for global ocean biogeochemistry models. Global Change Biology 11:2016-2040

Litchman E, Klausmeier CA, Miller JR, Schofield OM, Falkowksi PG (2006) Multi-nutrient, multi-group model of present and future oceanic phytoplankton communities. Biogeosciences 3:585-606

Litchman E, Klausmeier CA, Schofield OM, Falkowski PG (2007) The role of functional traits and trade-offs in structuring phytoplankton communities: scaling from cellular to ecosystem level. Ecology Letters 10:1-12

Lomas MW, Bonachela JA, Levin SA, Martiny AC 2014) Impact of ocean phytoplankton diversity on phosphate uptake. Proc. Nat. Acad. Sci. USA 111: 17540-17545.

Loureiro S, Jauzein C, Garcés E, Collos Y, Camp J, Vaqué D (2009) The significance of organic nutrients in the nutrition of Pseudo-nitzschia delicatissima (Bacillariophyceae). J Plankton Res 31:399-410

MacArthur R (1960) On the relative abundance of species. Amer Natural 94:25-36

Margalef R (1978) Life-forms of phytoplankton as survival alternatives in an unstable environment. Oceanol Acta 1:493-509

Margalef R (1997) Turbulence and marine life. Sci Mar Suppl 1 61:109-123

McKinney E, Gibson C, Stewart B (1997) Planktonic diatoms in the North-West Irish Sea: a study by automatic sampler. Biology and Environment: Proceedings of the Royal Irish Academy. Royal Irish Academy

Menden-Deuer S, Lessard EJ (2000) Carbon to volume relationships for dinoflagellates, diatoms, and other protist plankton. Limnology \& Oceanography 45:569-579

Merico A, Tyrrell T, Lessard EJ, Oguz T, Stabeno PJ, Zeeman SI, Whitledge TE (2004) Modelling phytoplankton succession on the Bering Sea shelf: role of climate influences and trophic interactions in generating Emiliania huxleyi blooms 19972000. Deep Sea Research Part I: Oceanographic Research Papers 51:1803-1826

Montagnes DJS, Kimmance SA, Atkinson D (2003) Using $Q_{10}$ : Can growth rates increase linearly with temperature? Aquatic Microbial Ecology 32:307-313 
803

804

805

806

807

808

809

810

811

812

813

814

815

816

817

818

819

820

821

822

823

824

825

826

827

828

829

830

831

832

833

834

835

836

837

838

839

840

841

842

843

844

845

846

Moore JK, Doney SC, Kleypas JA, Glover DM, Fung IY (2002) An intermediate complexity marine ecosystem model for the global domain. Deep-Sea Res II 49:403-462

Mutshinda CM, Finkel ZV, Widdicombe CE, Irwin AJ (2016) Ecological equivalence of species within phytoplankton functional groups. Funct Ecol:in press

Mutshinda CM, O'Hara RB, Woiwod IP (2009) What drives community dynamics? Proceedings of the Royal Society of London B: Biological Sciences 276:2923-2929

Mutshinda CM, O'Hara RB, Woiwod IP (2011) A multispecies perspective on ecological impacts of climatic forcing. J Animal Ecol 80:101-107

Mutshinda CM, O'Hara, RB (2011) Integrating the niche and neutral perspectives on community structure and dynamics. Oecologia 166: 241-251.

Najdek M, Blažina M, Djakovac T, Kraus R (2005) The role of the diatom Cylindrotheca closterium in a mucilage event in the northern Adriatic Sea: coupling with high salinity water intrusions. J Plankton Res 27:851-862

$\mathrm{R}$ Core Team (2016) R: A language and environment for statistical computing. $\mathrm{R}$ Foundation for Statistical Computing, Vienna, Austria

Raven J, Finkel Z, Irwin A (2005) Picophytoplankton: Bottom-up and top-down controls on ecology and evolution. VIE ET MILIEU-LIFE AND ENVIRONMENT 55:209-215

Raven JA (2011) The cost of photinhibition. Physiol Plant 142:87-104

Saitoh T, Chr N, Bjornstad ON (1997) Density dependence in fluctuating grey-sided vole populations. J Animal Ecol:14-24

Sher D, Thompson JW, Kashtan N, Croal L, Chisholm SW (2011) Response of Prochlorococcus ecotypes to co-culture with diverse marine bacteria. The ISME Journal 5:1125-1132

Sournia A, Chretiennot-Dinet M-J, Ricard M (1991) Marine phytoplankton: how many species in the world ocean? J Plankton Res 13:1093-1099

Stoecker DK (1999) Mixotrophy among dinoflagellates. Journal of Eukaryotic Microbiology 46:397-401

Sugihara G (1980) Minimal community structure: an explanation of species abundance patterns. Am Nat 116:770-787

Thomas A, O'Hara B, Ligges U, Sturtz S (2006) Making BUGS open. R news 6:12-17

Tsai A-Y, Chiang K-P, Chang J, Gong G-C (2005) Seasonal diel variations of picoplankton and nanoplankton in a subtropical western Pacific coastal ecosystem. Limnol Oceanogr 50:1221-1231

Vallina SM, Ward B, Dutkiewicz S, Follows M (2014) Maximal feeding with active preyswitching: A kill-the-winner functional response and its effect on global diversity and biogeography. Prog Oceanogr 120:93-109

van der Ploeg RR, Kirkham M (1999) On the origin of the theory of mineral nutrition of plants and the law of the minimum. Soil Sci Soc Am J 63:1055-1062

Westberry TK, Behrenfeld MJ, Siegel DA, Boss E (2008) Carbon-based primary productivity modeling with vertically resolved photoacclimation. Global Biogeochem Cycles 22:118

Widdicombe C, Eloire D, Harbour D, Harris R, Somerfield P (2010) Long-term phytoplankton community dynamics in the Western English Channel. J Plankton Res 32:643-655 
847 Williams PD, Hastings A (2011) Paradoxical persistence through mixed-system dynamics: 848 towards a unified perspective of reversal behaviours in evolutionary ecology.

849 Proceedings of the Royal Society of London B: Biological Sciences 278:1281-1290

850 Zheng L, Chen B, Liu X, Huang B, Liu H, Song S (2015) Seasonal variations in the effect of 851 microzooplankton grazing on phytoplankton in the East China Sea. Contin Shelf Res $852 \quad 111: 304-315$

853

854 